\title{
SHIFTING CLIMATE SENSITIVITY AND CONTRASTING GROWTH TRENDS IN JUNIPERUS SPECIES GROWING TOGETHER AT OPPOSITE RANGE MARGINS
}

\author{
JESS RIDDLE ${ }^{1,4 *}$, NEIL PEDERSON ${ }^{2}$, JOHN C. STELLA ${ }^{3}$, and DONALD J. LEOPOLD ${ }^{1}$ \\ ${ }^{1}$ Environmental and Forest Biology, State University of New York College of Environmental Science and Forestry, One \\ Forestry Drive, Syracuse, NY 13210, USA \\ ${ }^{2}$ Tree Ring Laboratory, Lamont-Doherty Earth Observatory and Columbia University, P.O. Box 1000, \\ Palisades, NY 10964, USA \\ ${ }^{3}$ Forest and Natural Resources Management, State University of New York College of Environmental Science and \\ Forestry, One Forestry Drive, Syracuse, NY 13210, USA
}

\begin{abstract}
The long generation time of woody plants inhibits detection of shifts in their distributions induced by climatic change. Consequently, assessing growth changes within existing populations, especially those near species range margins, can increase understanding of climate change impacts. We apply dendrochronological methods to examine recent radial growth of the ecologically similar species Juniperus communis L. and J. virginiana L. growing under the same conditions but at opposite latitudinal range margins. We use moving correlations to analyze changes in relationships between growth and monthly climatic variables, and regional curve standardization to identify trends in growth rate independent of plant age. For $J$. communis, growth sensitivity to temperature and precipitation shifted earlier in the spring whereas for J. virginiana only temperature sensitivity shifted earlier over the last 50 years. Since 1920, J. virginiana growth displays an upward trend, but J. communis growth shows both increases and decreases. Recent precipitation increase, rather than warming alone, appears to drive the growth trends, but interactions with temperature and vegetation dynamics, instead of range position, likely account for the differences in trends between species. Although these results generally agree with climate change predictions, they also point out potential difficulties in modeling future species ranges based on growth-climate relationships and growth at range margins.
\end{abstract}

Keywords: climate change, Cupressaceae, dendrochronology, growth rate trends, Juniperus virginiana, Juniperus communis, precipitation, shrubs, species distributions, temperature, trees.

\section{INTRODUCTION}

Rapid climate warming during the $21^{\text {st }}$ Century will likely significantly impact woody plants because of the many effects of temperature on biochemical and ecological processes (Schenk 1996; IPCC 2007). Pollen records show that tree species responded to warming in the Quaternary by shifting their ranges poleward, suggesting that future impacts will include distribution changes (Davis and Shaw 2001). However, the rate of

\footnotetext{
${ }^{4}$ Current address: School of Forest Resources, University of Arkansas at Monticello, P.O. Box 3468, Monticello, AR 71656, USA

*Email: Jess.Riddle@gmail.com
}

current warming raises concerns that species may not be able to migrate fast enough to avoid adverse impacts (Thomas et al. 2004). The long generation time of woody plants may cause climate change effects to first manifest in living individuals before changes occur in species distributions or forest composition.

Dendrochronological studies have documented two primary responses of woody plants to climate change: changes in radial growth rates (e.g. Barber et al. 2000); and shifts in both magnitude and timing of growth sensitivity (Linderholm 2002; Carrer and Urbinati 2006; Carrer et al. 2007). The most common responses include decreased growth with higher temperature 


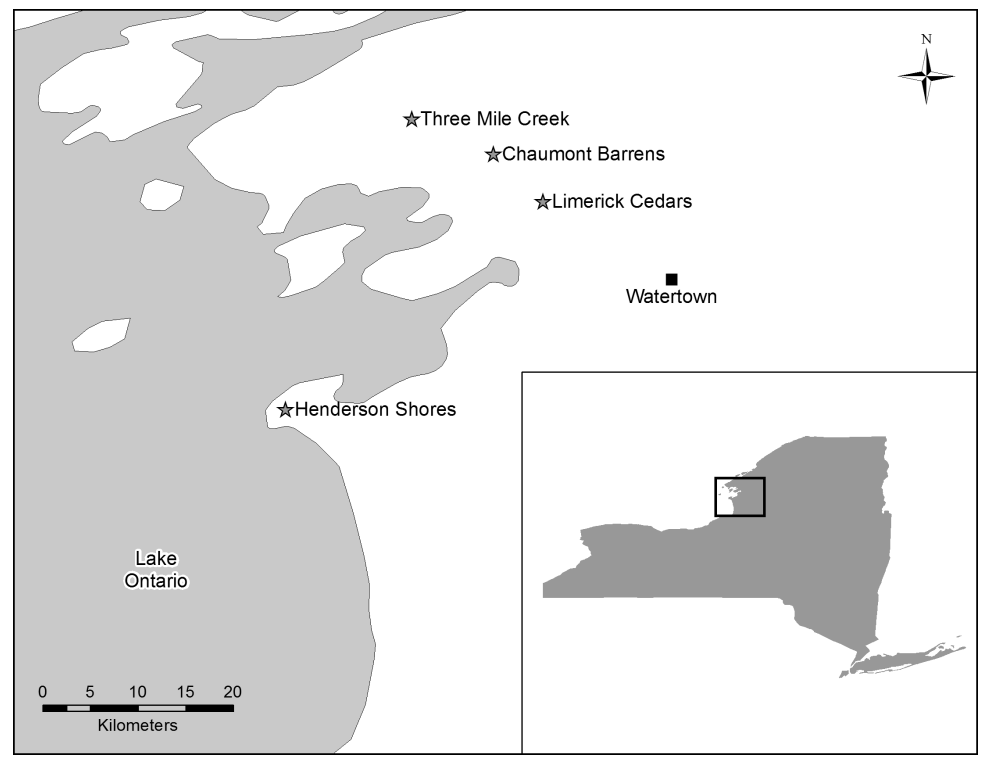

Figure 1. Location of the study sites within New York State, USA.

across many biomes (e.g. Barber et al. 2000), but higher growth in some alpine and boreal species (Wilmking et al. 2004; Salzer et al. 2009). Changes in growth sensitivity include responses to growing season lengthening (Carrer and Urbinati 2006), increasing drought stress (Lloyd and Fastie 2002), and shifts in timing of sensitivity to water stress (Biondi 2000; Macias et al. 2006).

Juniperus species in New York State (NYS), USA provide a rare opportunity to examine how mature woody plants respond to changing climate. This region contains part of a narrow band in which the broad ranges of $J$. virginiana L. (eastern redcedar) and $J$. communis L. (common juniper) overlap at their respective northern and southern range margins (Little 1971; Figure 1). Though sharing many similar ecological characteristics, the two species differ in growth habit and biogeographic distribution. J. virginiana is widespread throughout temperate eastern North America (Little 1971) and grows as a small- to mediumsized tree, whereas $J$. communis grows primarily as a shrub throughout boreal and alpine North America and Eurasia (Lawson 1990; Gleason and Cronquist 1991; Thomas et al. 2007). The decline of some Juniperus species, apparently in response to climate change (Fisher and Gardner 1995; Fisher 1997), highlights the need for a better understanding of how Juniperus responds to environmental change. For example, J. communis has expanded into some alpine grasslands (SanzElorza et al. 2003), but low seed production and seed survival in low latitude populations suggest they are under more pressure than in northern populations (Garcia et al. 2000). In contrast, range models predict $J$. virginiana will have among the greatest expansions of eastern North American trees (Iverson et al. 2005).

In this study, we examined changes in $J$. virginiana and $J$. communis growth in the context of changing climate by collecting core samples and cross-sections from four sites in NYS where the species co-occur, which allows us to evaluate the growth response with minimal confounding influences. The specific objectives were to identify: (1) trends in precipitation and temperature within the study area; and within that context evaluate, (2) shifts in growth sensitivity to seasonal climate drivers, and (3) radial growth rate trends over the last nine decades. Prior research indicates that $J$. virginiana responds positively to precipitation and negatively to high temperature during the early growing season (e.g. McGinnes et al. 1983). J. communis growth response in temperate climates is unknown, but it responds positively to warm growing seasons at tree line (Hantemirov et al. 
2011). If both temperature and precipitation are increasing, we anticipate $J$. virginiana growth will increase, because the species is adapted to warmer regions and previously studied populations are water limited (McGinnes et al. 1983; Maxwell et al. 2012). The lack of literature on J. communis growing in unusually warm habitats makes it difficult to predict the species' growth trend. We expect that an earlier growing season associated with warming will lead to earlier climate response in both species.

This study differs from most research in several ways. Most range-margin tree-ring studies focus on trees growing in climates near the arid or cold limits of forest tolerance, but not both (though see Soldberg et al. 2002). In contrast, Juniperus in NYS grows in a climate with few climatic extremes. Nevertheless, the climate of the northeastern US is changing, and in contrast to many dendrochronological study regions (e.g. Jump et al. 2006), not only temperature but also precipitation is increasing (Huntington et al. 2009). As a result, soil moisture over the past four decades is apparently higher than any other time in the last 500 years (Pederson et al. 2013).

\section{METHODS}

\section{Study Sites}

The four study sites (Chaumont Barrens, Henderson Shores, Limerick Cedars, and Three Mile Creek) lie in the cool temperate climate of NYS and within $8 \mathrm{~km}$ of Lake Ontario (Figure 1). Precipitation is evenly distributed throughout the year (1920-2008 mean $860 \mathrm{~mm}$ ), with winter precipitation falling as snow and increased by lake effect. Mean monthly temperatures range from $-6.9^{\circ} \mathrm{C}$ in January to $20.6^{\circ} \mathrm{C}$ in July (Daly 1994). Forests dominate the region, but thin soils over level limestone at the study sites support a mosaic of forest, woodland, shrubland, and prairie known as alvars (Edinger et al. 2002). All study sites were likely cleared and grazed in the late 1800s or early 1900s (Gilman 1995). Juniperus virginiana dominates most of the woodland communities, and J. communis is a major component of the shrubland communities.

\section{Sample Collection and Preparation}

We targeted the oldest-looking individuals for sampling, because most individuals appeared younger than the available climate records. We collected core samples from living $J$. virginiana and $J$. communis, two per individual, and cut crosssections from dead J. communis. J. virginiana cores were collected at approximately $1.5 \mathrm{~m}$ and $J$. communis samples as close to the base as possible, often $c a .0 .5 \mathrm{~m}$ above ground surface.

To clearly see ring details, core samples were dried, stabilized, and sanded with progressively finer sandpaper. We crossdated samples via skeleton plots and the temporal pattern of false rings. Crossdated ring widths were measured using a sliding stage micrometer (Velmex Corporation, Bloomfield, NY). Finally, the computer program COFECHA was used to check the crossdating (Holmes 1983).

\section{Climate Data and Analysis}

We obtained A.D. 1920 to 2008 monthly precipitation and mean maximum and minimum temperatures interpolated for each site from PRISM (Daly 1994). We assumed that reliability of the climate data increased in 1920, because monthly climate summaries from the Watertown, NY weather station, $10-30 \mathrm{~km}$ from the study sites, begin at that time (National Climate Data Center 2012). In cases where the four sites were analyzed as a composite, the mean of the climate series was used. We assessed temporal trends in monthly climate variables with linear regressions in R (R Development Core Team 2010).

\section{Climate-Growth Relationship Analysis}

We detrended the ring widths from each radius sampled to isolate the short-term variation in ring widths, which is presumably a result of inter-annual weather variation (Cook et al. 1990a). This detrending was accomplished by fitting a Friedman variable span smoother $(\alpha=$ 8 ) to each series and dividing the ring widths by the fit values (Friedman 1984). That procedure results in a set of dimensionless index values with a mean of one and constant variance. Using the 
program ARSTAN, all series were then grouped by site, autoregressively modeled, and averaged by year using a robust biweight mean to produce site chronologies for each species (Cook 1985; Cook et al. 1990b). Finally, composite chronologies were computed for each species as the arithmetic mean of the site chronologies.

We used moving correlations, which are Pearson correlations calculated using a set number of years and advanced one year at a time, with a window width of 30 years to examine changes over time in climate-growth relationships. Moving correlations were restricted to the period after 1957 so that all sites would be included and changes would not merely reflect the incorporation of a new site. We considered a change significant only if the correlation was significantly different from zero for one period and had the opposite sign during another period. Correlations were calculated in R ( $\mathrm{R}$ Development Core Team 2010).

\section{Radial Growth Trend Analysis}

We used two detrending methods to examine growth rate trends: negative exponential detrending and regional curve standardization (RCS). These detrending methods rely on different assumptions, so the chronologies have the potential to provide complimentary estimates of growth trend. Negative exponential detrending attempts to remove size/age related patterns by fitting a negative exponential curve to each series if possible, or if not, by fitting a linear regression of negative slope (Cook et al. 1990a). If ring widths do not decline with age, then they are standardized by dividing by the mean. Conversely, RCS empirically estimates a single expected growth curve by averaging ring widths by the tree's age at the time of ring formation; the first ring is averaged for all individuals, then the second, and so forth (Briffa et al. 1992). The series are not aligned by calendar date, so the climate signal is assumed to be incoherent and absent from the regional growth curve. For both methods, ringwidth series were divided by the expected growth curves to produce dimensionless index values that were all averaged using a biweight mean to produce chronologies (Cook et al. 1990b). Negative exponential detrending was completed in ARSTAN (Cook 1985) and RCS chronologies were produced with the dplR package in $\mathrm{R}$ (Bunn 2010).

Modifications were sometimes necessary to minimize potential biases in the chronologies. We removed the last 20 years from all dead $J$. communis series, because growth shortly prior to death may not be representative of population patterns (Bigler and Bugmann 2004). Series were not modified to account for years missing between the innermost ring and the pith, which can distort the regional growth curve shape. Biases in RCS caused by missing years are typically small (Esper et al. 2003), and the highly eccentric piths and irregular variation of ring width around the circumference of $J$. communis samples make them inappropriate for estimating the number of years missing. Sampling trees from a single cohort can also distort the regional curve by allowing the curve to retain a climate signal and other high- to medium-frequency signals, but continual recruitment of both species at the study sites minimized cohort-related errors.

For the RCS chronologies, we took the additional step of averaging separate chronologies comprising only slow or fast growing individuals to produce the final chronology. That grouping and averaging combats potential biases that arise from variation with time and tree age in the probability of sampling an inherently fast or slow growing tree (Melvin 2004; Riddle 2011; biases reviewed by Briffa and Melvin 2011). Regional curves were first produced using all individuals of each species. Next, for each series, we calculated the sum of the ring widths and the sum of the regional curve values up to the age of the series (i.e. the expected radius). Dividing the actual radius by the radius expected for an individual that age then produced an estimate of growth rate independent of plant age and size (relative growth rate), and allowed comparison of growth rates among plants. For each species, we ranked radii by relative growth rate, calculated separate RCS chronologies based on fast and slow growing individuals, and averaged the two resulting chronologies to produce the final chronology. 
Table 1. Trends in monthly climate variables as estimated by linear regression for the study region over 1920-2008. Bold indicates significance at $\mathrm{p}<0.05$.

\begin{tabular}{lccc}
\hline Month & $\begin{array}{c}\text { Precipitation } \\
(\text { mm/decade })\end{array}$ & $\begin{array}{c}\text { Maximum } \\
\text { Temperature } \\
\left({ }^{\circ} \text { C/decade }\right)\end{array}$ & $\begin{array}{c}\text { Minimum } \\
\text { Temperature } \\
\left({ }^{\circ} \text { C/decade }\right)\end{array}$ \\
\hline January & 2.3 & 0.10 & 0.06 \\
February & 0.9 & 0.17 & 0.02 \\
March & 0.8 & 0.07 & -0.12 \\
April & 2.1 & 0.13 & 0.01 \\
May & 2.2 & 0.10 & 0.06 \\
June & 2.1 & 0.02 & 0.04 \\
July & 1.7 & -0.03 & 0.01 \\
August & $\mathbf{2 . 8}$ & 0.00 & -0.01 \\
September & $\mathbf{3 . 5}$ & -0.01 & -0.06 \\
October & $\mathbf{3 . 1}$ & -0.04 & -0.01 \\
November & $\mathbf{3 . 6}$ & 0.14 & 0.03 \\
December & $\mathbf{2 . 3}$ & $\mathbf{0 . 2 3}$ & 0.15 \\
Annual & $\mathbf{2 7 . 3}$ & 0.08 & 0.01 \\
\hline
\end{tabular}

\section{RESULTS}

Total monthly precipitation in the study region has increased for all months since 1920, and trends are significant for each month of August through December (Table 1). Annual precipitation has increased at a rate of $27 \mathrm{~mm} /$ decade $(\mathrm{p}<0.0001)$, resulting in an increase of nearly $33 \%$ since 1920 . Maximum temperatures have increased for most months, but the trend is only significant for December $\left(0.23^{\circ} \mathrm{C} /\right.$ decade; $\mathrm{p}<$ $0.05)$. In general, winter and spring maximum temperatures have increased while summer and fall maximum temperatures have remained stable. Minimum temperatures show less variability with the largest changes occurring in March $\left(-0.12^{\circ} \mathrm{C} /\right.$ decade), and December $\left(+0.15^{\circ} \mathrm{C} /\right.$ decade $)$.

The expressed population signal, a measure of chronology quality (Wigley et al. 1984), remains $>0.85$ for all chronologies from 1958-2008. The growth-climate relationships of both species vary temporally, and some variation is present in all months (Figure 2). Though changes in most growth-climate relationships are not statistically significant $(\mathrm{p}<0.05)$, there is a coherent shift at the beginning of the growing season (Figure 2). There has been a shift from April to March with maximum temperature for both species, and a similar timing shift with minimum temperature for $J$. virginiana only. Similarly, the J. communis response to precipitation has shifted from MayJuly to April-June, but $J$. virginiana does not show a comparable shift. Other fluctuations reflect a change in intensity rather than a change in timing. For example, the $J$. virginiana relationship with prior July minimum temperature has switched from significantly positive to significantly negative, and the $J$. communis March precipitation response has oscillated. In most cases, seasonal growth/climate relationships are stable over time, for example the strong positive growth response of $J$. communis to May and June precipitation.

Chronologies produced through negative exponential detrending and regional curve standardization reveal similar trends in $J$. communis growth (Figure 3a, b): relatively low growth from 1920 to the early 1960s, high growth from 1968 to 2003, and a recent steep decline. The chronologies differ in the range between low and high growth periods, and in the declining growth trend in the RCS chronology from the 1970s to 2003. Except for the Limerick Cedar chronology increasing from 1980 to 2000, RCS site chronologies (Figure 4a) generally resemble each other.

The two J. virginiana chronologies show more mid-frequency variability and a sinusoidal pattern, with growth peaks in the late 1930s, late 1950s, early 1980s, and since 2002 (Figure 3c, d). The growth peaks coincide between the chronologies, but the two detrending methods yield different trends. The negative exponential chronology shows no overall trend, but the RCS chronology indicates a long-term growth increase spanning the sample period. Except for the decline at Henderson Shores around 1970, the RCS site chronologies (Figure $4 b$ ) are generally coherent.

\section{DISCUSSION}

We found contrasting trends in radial growth rates of two closely related species growing at opposite range margins (Figure 3). The two species grew amongst each other on the same sites, so neither climate nor site conditions account for the contrasting trends. Consistency of that result across sites suggests the influence of broadscale drivers, and the growth trends coincide 


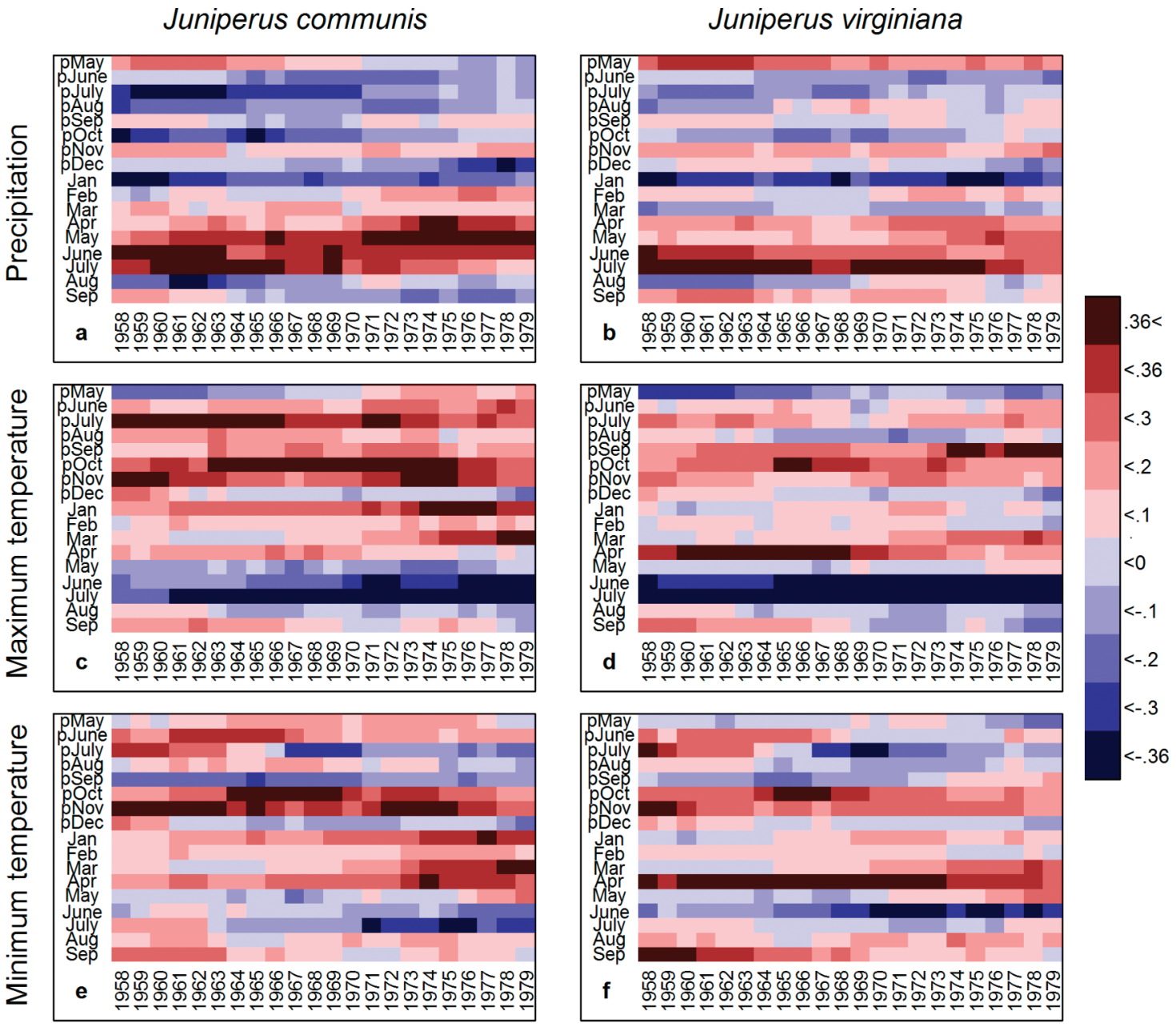

First year

Figure 2. Correlations between radial growth and monthly climatic variables calculated on overlapping 30-year windows staggered by one year. Each column represents one window starting with 1958 to 1987 and proceeding to 1979 to 2008. Each row represents one month from the May prior to ring formation to September of the year of ring formation. Reds denote positive correlations, blues negative correlation, darker shades stronger correlations, and the darkest shade of each color is statistically significant at $\mathrm{p}<$ 0.05. Correlations are presented for Juniperus communis (a, c, and e) and J. virginiana (b, d, and f) using total precipitation (a and b), mean maximum temperature (c and d), and mean minimum temperature (e and $\mathrm{f}$ ).

with strongly increasing precipitation (Table 1, Figure 4). Slightly weaker trends in winter and spring warming may also contribute to Juniperus communis climate sensitivity shifting to earlier in the year, especially increased March sensitivity (Table 1, Figure 2). Other factors, such as increased competition, may contribute to the growth trends and climate response shifts, but confirming their roles will require additional investigation.
Many of these results agree with general predictions about climate change effects on the range margins of woody plant populations.

\section{Climate Trends}

The study region has become significantly wetter during the summer, fall, and annually (Table 1). Conversely, local minimum and 

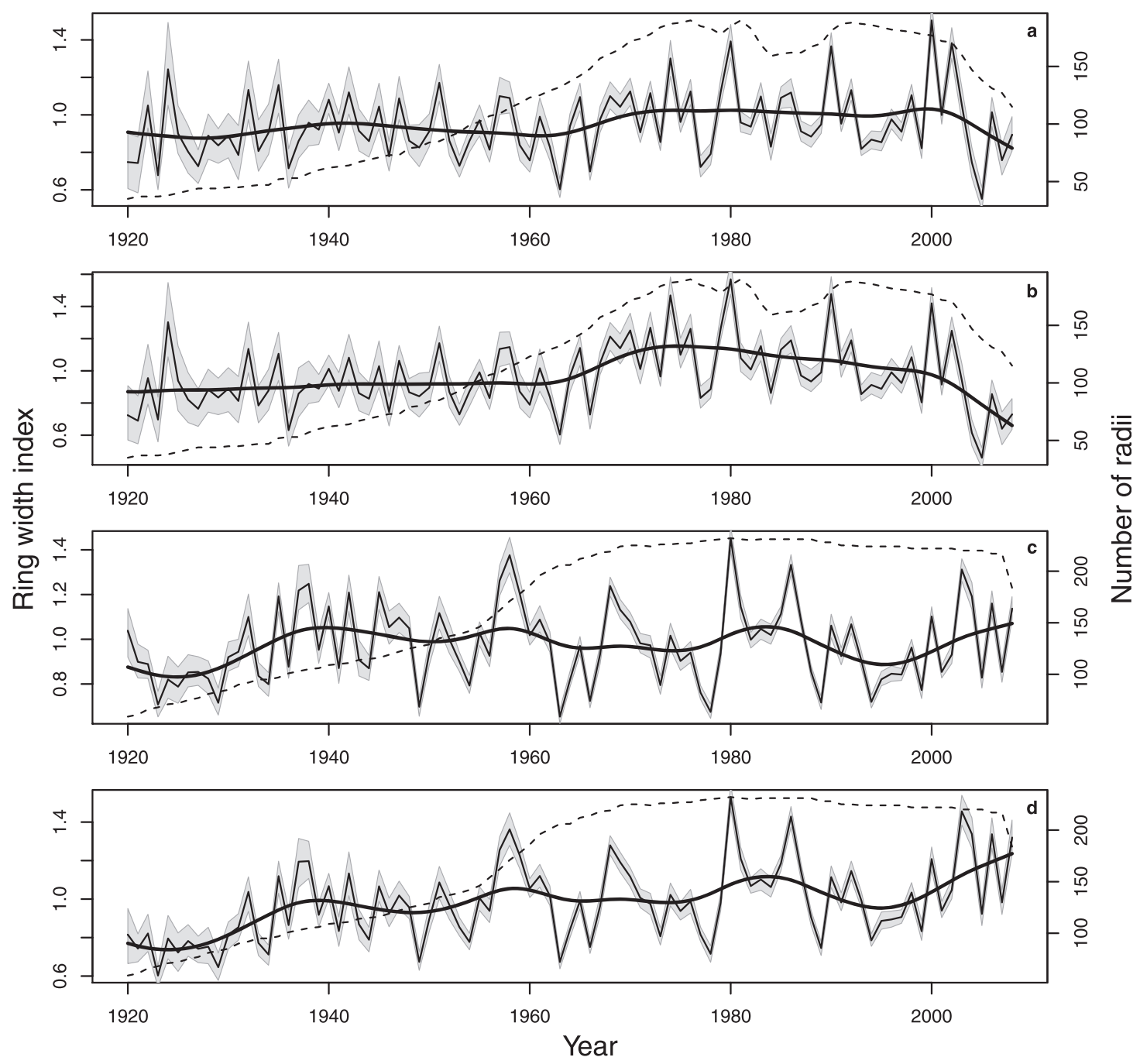

Figure 3. Chronologies (thin black lines) of Juniperus communis (a and b) and J. virginiana (c and d) radial growth produced by either negative exponential detrending ( $a$ and $c$ ) or regional curve standardization ( $b$ and $d$ ). Bold lines are smoothed chronologies produced using cubic smoothing splines with $50 \%$ frequency cut-off set to 20 years, shaded gray regions are $95 \%$ bootstrap confidence intervals, and dashed lines indicate the number of radii included in the chronologies.

maximum temperature trends are not significant for annual means and only rarely for individual months. The relatively large interannual variability of all three sets of variables hinders the detection of clear trends, and thus lack of statistical significance should not be interpreted as biological insignificance. Indeed, local maximum temperatures in each month November through May have increased more than global mean annual temperature (IPCC 2007). The local precipitation pattern matches the regional moisture trend extending back to the 1800 s, and a proxy reconstruction indicates the last 43 years have been the wettest in the last 500 in southeastern NYS (Pederson et al. 2013).

\section{Changes in Growth-Climate Relationships}

Paralleling recent phenology shifts noted in diverse taxa worldwide (Parmesan and Yohe 


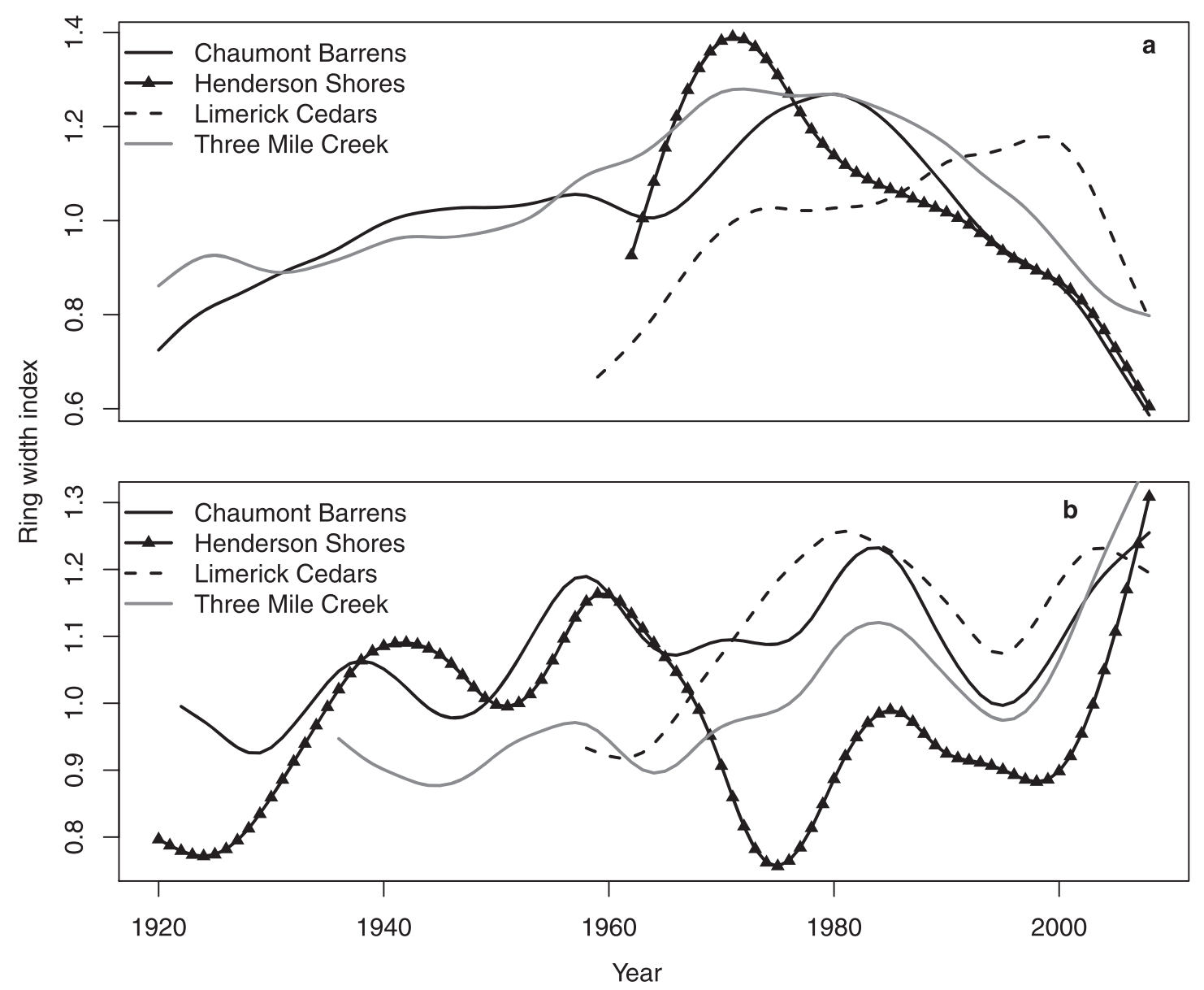

Figure 4. Smoothed regional curve standardization site chronologies for Juniperus communis (a) and J. virginiana (b). Chronologies were smoothed with cubic smoothing splines with $50 \%$ frequency cut-off set to 20 years.

2003), the shifts in climate-growth relationships around the start of the growing season stand out as the strongest and most consistent found in our investigation. $J$. communis responses to both precipitation and temperature have shifted earlier, and $J$. virginiana shows coincident temperature shifts. J. virginiana can attain positive net photosynthetic rates during winter at temperatures as low as $4^{\circ} \mathrm{C}$, so increasing March maximum temperatures may allow both species to gain carbon earlier (Lassoie et al. 1983). Earlier onset of growth triggered by May warming would also allow evapotranspiration to deplete soil moisture from the thin soils at the study sites earlier. Consequently, these processes can increase growth sensitivity to precipitation earlier in the year.

Similar to this study, Juniperus communis growing at arctic tree line in Russia shifted towards earlier temperature sensitivity during a period of increasing winter precipitation and early growing season warming (Hantemirov et al. 2011). In contrast, West Virginia J. virginiana showed stable May precipitation response (Maxwell et al. 2012). Studying an evergreen conifer at an arid ecotone with a non-forest ecosystem, similar to this study, Biondi (2000) identified drier soils caused by earlier snowmelt as the likely cause of earlier precipitation response. Research suggests that $\mathrm{CO}_{2}$ fertilization and aging, hypothesized 
sources of changing climate-growth relationships in other species, reduce climate sensitivity in Juniperus spp. (Knapp and Soulé 2008; Rozas et al. 2009). Hence, those factors are less likely to explain the increased spring sensitivity observed here. When we analyzed our data using moving Spearman correlations, the similarity of results (data not shown) indicate that outliers are not responsible for the observed shifts. Thus, spring warming most likely explains the increased sensitivity around the early growing season, because the pattern occurs in both species, with both temperature and precipitation, and is coupled with reduced sensitivity later in the growing season.

\section{Trends in Growth Rates}

$J$. virginiana radial growth remains constant or increases slightly throughout the period examined, but $J$. communis displays distinct phases of increasing then decreasing growth and a recent abrupt decline (Figure 3). These results were generally consistent across sites (Figure 4), suggesting that broad-scale drivers likely drive the trends. However, some variation also occurs between detrending methods. J. virginiana growth increases more in the RCS chronology than the negative exponential chronology. Ends of RCS chronologies may be distorted by various biases (Briffa and Melvin 2011), but we reduced that potential error by averaging the chronologies from slow and fast growing individuals (Melvin 2004). Negative exponential detrending will remove an increasing growth trend if improved growing conditions merely slow size-related ring width decline rather than increase raw ring widths (Melvin and Briffa 2008). Hence, the data suggest $J$. virginiana radial growth is increasing. Similarly, the ability of negative exponential detrending to fit growth declines regardless of their cause may have removed the $J$. communis declining trend between 1970 and 2000, which is seen in the RCS chronology.

Among broad-scale drivers, increasing precipitation has likely had the strongest effect on $J$. virginiana radial growth. J. virginiana's strongest positive correlations are with precipitation, and precipitation has increased by more than $10 \mathrm{~mm}$ per month during the growing season. Although warming could account for increased growth, positive correlations with temperature are not as strong as those with precipitation, and warmth during May (increasing $0.10^{\circ} \mathrm{C} /$ decade) decreases growth. The abrupt, early 1970s decrease in ring width at Henderson Shores may reflect a localized disturbance (Figure 4), such as an ice storm, which would affect $J$. virginiana more than $J$. communis, because the former's larger size would leave it more vulnerable to mechanical damage.

Given the similarity of $J$. virginiana and $J$. communis climate-growth relationships, the lack of any $J$. communis growth trend after the 1960s (Figure 3), in contrast to J. virginiania's clear increase, is surprising. Common habitat and ecology rule out pollution and most other broad scale factors. Extreme high temperatures, or other heat effects not captured in correlations with monthly temperature variables, could limit growth in the more northern $J$. communis, but no data are available on those effects. If poor health gave the appearance of age, sampling bias could account for stable to declining growth in $J$. communis. However, growth at Limerick Cedars increases until approximately A.D. 2000 despite the same protocols for selecting individuals to sample, and the RCS chronology comprising only individuals with above-average growth rates still shows a post-1970 declining trend. Finally, increasing competition from other shrub species could limit growth of $J$. communis but affect the larger $J$. virginiana less. Precipitation increases can increase shrub density in shrublands (Brown et al. 1997), and invasive shrubs, common at all study sites, can reduce radial growth of natives (Hartman and McCarthy 2007).

\section{CONCLUSIONS}

These results suggest that even in a climate where neither cold nor aridity limits the extent of forests, climate change can strongly impact radial growth rates and the timing of climate sensitivity. Range margin effects may contribute to these impacts, but knowing a population's position within its range is not sufficient to predict trends; southern range margin $J$. communis growth trends changed over time and varied among sites. 
Similarly, knowing a species' response to monthly climatic variables may not be sufficient to predict responses to climate change; $J$. virginiana and $J$. communis growing on the same sites resemble each other in climate response, but growth trends differ between the species. Hence, additional research on how climate change interacts with edaphic conditions, extreme events, and local ecology could help predict future radial growth trends (Linares et al. 2009; Matias and Jump 2012).

\section{ACKNOWLEDGMENTS}

We appreciate The Nature Conservancy and the New York State Department of Environmental Conservation allowing us to collect samples. We thank Edward Bevilacqua for use of his treering measuring equipment. We also thank two anonymous reviewers for their helpful feedback.

\section{REFERENCES CITED}

Barber, V. A., G. P. Juday, and B. P. Finney, 2000. Reduced growth of Alaskan white spruce in the twentieth century from temperature-induced drought stress. Nature 405: 668-672.

Bigler, C., and H. Bugmann, 2004. Predicting the time of tree death using dendrochronological data. Ecological Applications 14:902-914.

Biondi, F., 2000. Are climate-growth relationships changing in north-central Idaho, USA? Arctic, Antarctic, and Alpine Research 32:111-116.

Briffa, K. R., and T. M. Melvin, 2011. A closer look at regional curve standardisation of tree-ring records: Justification of the need, a warning of some pitfalls, and suggested improvements in its application. In Dendroclimatology: Progress and prospects, edited by M. K. Hughes, H. F. Diaz, and T. W. Swetnam, pp. 113-146. Springer Verlag, New York.

Briffa, K. R., P. D. Jones, T. S. Bartholin, D. Eckstein, F. H. Schweingruber, W. Karlén, P. Zetterberg, and M. Eronen, 1992. Fennoscandian summers from A.D. 500: Temperature changes on short and long timescales. Climate Dynamics 7: 111-119.

Brown, J. H., T. J. Valone, and C. G. Curtin, 1997. Reorganization of an arid ecosystem in response to recent climate change. Proceedings of the National Academy of Sciences 94(18):9729-9733.

Bunn, A. G., 2010. Statistical and visual crossdating in R using the dplR library. Dendrochronologia 28:251-258.

Carrer, M., and C. Urbinati, 2006. Long-term change in the sensitivity of tree-ring growth to climate forcing in Larix decidua. New Phytologist 170:861-872.

Carrer, M., P. Nola, J. L. Eduard, R. Motta, and C. Urbinati, 2007. Regional variability of climate-growth relationships in
Pinus cembra high elevation forests in the Alps. Journal of Ecology 95:1072-1083.

Cook, E. R., 1985. A Time-Series Analysis Approach to Tree-Ring Standardization. Ph.D. dissertation. University of Arizona, Tucson.

Cook, E. R., K. R. Briffa, S. G. Shiyatov, and V. Mazepa, 1990a. Tree-ring standardization and growth-trend estimation. In Methods of Dendrochronology: Applications in the Environmental Sciences, edited by E. R. Cook, and L. Kairiukstis, pp. 104-122. Kluwer Academic Publishers, Boston.

Cook, E. R., S. G. Shiyatov, and V. Mazepa, 1990b. Estimation of the mean chronology. In Methods of Dendrochronology: Applications in the Environmental Sciences, edited by E. R. Cook, and L. Kairiukstis, pp. 123-132. Kluwer Academic Publishers, Boston.

Daly, C., 1994. A statistical-topographic model for mapping climatological precipitation over mountainous terrain. Journal of Applied Meteorology 33:140-158.

Davis, M. B., and R. G. Shaw, 2001. Range shifts and adaptive responses to Quaternary climate change. Science 282: 673-679.

Edinger, G. J., D. J. Evans, S. Gebauer, T. G. Howard, D. M. Hunt, and A. M. Olivero, 2002. Ecological Communities of New York State (2nd ed.). New York Natural Heritage Program, New York State Department of Environmental Conservation, Albany, New York.

Esper, J., E. R. Cook, P. J. Krusic, K. Peters, and F. H. Schweingruber, 2003. Tests of the RCS method for preserving low-frequency variability in long tree-ring chronologies. Tree-Ring Research 29:81-98.

Fisher, M., 1997. Decline in the juniper woodlands of Raydah Reserve in southwestern Saudi Arabia: A response to climate changes? Global Ecology and Biogeography Letters 6:379-386.

Fisher, M. A., and A. S. Gardner, 1995. The status and ecology of a Juniperus excelsa subsp. polycarpos woodland in the northern mountains of Oman. Vegetatio 119:33-51.

Friedman, J. H., 1984. A Variable Span Smoother. Technical Report LCS 5, Department of Statistics, Stanford University, Palo Alto, California.

Garcia, D., R. Zamora, J. M. Gomez, P. Jordano, and J. A. Hodar, 2000. Geographical variation in seed production, predation, and abortion in Juniperus communis throughout its range in Europe. The Journal of Ecology 88:436-446.

Gilman, B., 1995. Vegetation of Limerick Cedars: Pattern and Process in Alvar Communities. Ph.D. dissertation. SUNY College of Environmental Science and Forestry, Syracuse, New York.

Gleason, H. A., and A. Cronquist, 1991. Manual of Vascular Plants of Northeastern United States and Adjacent Canada (2nd ed.). New York Botanical Garden, New York.

Hantemirov, R. M., S. G. Shiyatov, and L. A. Gorlanova, 2011. Dendroclimatic study of Siberian juniper. Dendrochronologia 29:119-122.

Hartman, K., and B. McCarthy, 2007. A dendro-ecological study of forest overstorey productivity following the invasion of the non-indigenous shrub Lonicera maackii. Applied Vegetation Science 10:3-14. 
Holmes, R., 1983. Computer-assisted quality control in treering dating and measurement. Tree-Ring Bulletin 44:69-75.

Huntington, T. G., A. D. Richardson, K. J. McGuire, and K. Hayhoe, 2009. Climate and hydrological changes in the northeastern United States: Recent trends and implications for forested and aquatic ecosystems. Canadian Journal of Forest Research 39:199-212.

IPCC, 2007. Fourth assessment report-climate change 2007. Intergovernmental Panel on Climate Change, Cambridge University Press, Cambridge.

Iverson, L. R., A. M. Prasad, and M. W. Schwartz, 2005. Predicting potential changes in suitable habitat and distribution by 2100 for tree species of the eastern United States. Journal of Agricultural Meteorology 61:29-37.

Jump, A. S., J. M. Hunt, and J. Penuelas, 2006. Rapid climate change-related growth decline at the southern range edge of Fagus sylvatica. Global Change Biology 12: 2163-2174.

Knapp, P. A., and P. T. Soulé, 2008. Use of atmospheric $\mathrm{CO}_{2^{-}}$ sensitive trees may influence dendroclimatic reconstructions. Geophysical Research Letters 35:L24703.

Lassoie, J. P., P. M. Dougherty, P. B. Reich, T. M. Hinckley, C. M. Metcalf, and S. J. Dina, 1983. Ecophysiological investigations of understory eastern redcedar in central Missouri. Ecology 64:1355-1366.

Lawson, E. R., 1990. Juniperus virginiana L. eastern redcedar. In Silvics of North America: 1 Conifers, edited by R. M. Burns, and B. H. Honkala. US Department of Agriculture, Forest Service, Washington DC.

Linares, J. C., J. J. Camarero, and J. A. Carreira, 2009. Interacting effects of changes in climate and forest cover on mortality and growth of the southernmost European fir forests. Global Ecology and Biogeography 18:485-497.

Linderholm, H. W., 2002. Twentieth-century scots pine growth variations in the central Scandinavian Mountains related to climate change. Arctic, Antarctic, and Alpine Research 34: 440-449.

Little, E. L. Jr., 1971. Atlas of United States Trees, Volume 1, Conifers and Important Hardwoods. Miscellaneous Publication 1146, US Department of Agriculture.

Lloyd, A. H., and C. L. Fastie, 2002. Spatial and temporal variability in the growth and climate response of treeline trees in Alaska. Climatic Change 52:481-509.

Macias, M., L. Andreu, O. Bosch, J. Camarero, and E. Gutiérrez, 2006. Increasing aridity is enhancing silver fir (Abies alba Mill.) water stress in its south-western distribution limit. Climatic Change 79:289-313.

Matias, L., and A. S. Jump, 2012. Interactions between growth, demography, and biotic interactions in determining species range limits in a warming world: The case of Pinus sylvestris. Forest Ecology and Management 282:10-22.

Maxwell, R. S., A. E. Hessl, E. R. Cook, and B. M. Buckley, 2012. A multicentury reconstruction of May precipitation for the Mid-Atlantic region using Juniperus virginiana tree rings. Journal of Climate 25:1045-1056.

McGinnes, Jr., E. A., R. P. Guyette, K. R. Kreft, and J. M. Burroughs, 1983. Climate, fire, and stream runoff histories based on analysis of old redcedar of the Ozarks. Journal of
Applied Polymer Science, Applied Polymer Symposium 37: 1097-1115.

Melvin, T. M., 2004. Historical Growth Rates and Changing Sensitivity of Boreal Conifers. Ph. D. dissertation, University of East Anglia, Norwich, UK.

Melvin, T. M., and K. R. Briffa, 2008. A "signal-free" approach to dendroclimatic standardisation. Dendrochronologia 26:71-86.

National Climatic Data Center, 2012. Climate Data Online. Website: www7.ncdc.noaa.gov/CDO/cdo. US Department of Commerce.

Parmesan, C., and G. Yohe, 2003. A globally coherent fingerprint of climate change impacts across natural systems. Nature 421:37-42.

Pederson, N., A. R. Bell, E. R. Cook, U. Lall, N. Devineni, R. Seager, K. Eggleston, and K. J. Vranes, 2013. Is an epic pluvial masking the water insecurity of the greater New York City region? Journal of Climate 26:1339-1354.

R Development Core Team, 2010. R: A language and environment for statistical computing. R Foundation for Statistical Computing, Vienna, Austria.

Riddle, J., 2011. Growth-Climate Relationships of Juniperus communis and Juniperus virginiana at contrasting range margins. M.S. thesis, SUNY College of Environmental Science and Forestry, Syracuse, New York.

Rozas, V., L. Desoto, and J. M. Olano, 2009. Sex-specific, agedependent sensitivity of tree-ring growth to climate in the dioecious tree Juniperus thurifera. New Phytologist 182:687-697.

Salzer, M. W., M. K. Hughes, A. G. Bunn, and K. F. Kipfmueller, 2009. Recent unprecedented tree-ring growth in bristlecone pine at the highest elevations and possible causes. Proceeding of the National Academy of Sciences 106: 20348-20353.

Sanz-Elorza, M., E. D. Dana, A. González, and E. Sobrino, 2003. Changes in the high-mountain vegetation of the central Iberian Peninsula as a probable sign of global warming. Annals of Botany 92:273-280.

Schenk, H. J., 1996. Modeling the effects of temperature on growth and persistence of tree species: A critical review of tree population models. Ecological Modelling 92:1-32.

Thomas, C. D., A. Cameron, R. E. Green, M. Bakkenes, L. J. Beaumont, Y. C. Collingham, B. F. N. Erasmus, M. F. De Siqueira, A. Grainger, L. Hannah, L. Hughes, B. Huntley, A. S. Van Jaarsveld, G. F. Midgley, L. Miles, M. A. OrtegaHuerta, A. T. Peterson, O. L. Phillips, and S. E. Williams, 2004. Extinction risk from climate change. Nature 427:145-148.

Thomas, P. A., M. El-Barghathi, and A. Polwart, 2007. Biological flora of the British Isles: Juniperus communis L. Journal of Ecology 95:1404-1440.

Wigley, T. M. L., K. R. Briffa, and P. D. Jones, 1984. On the average value of correlated time series, with applications in dendroclimatology and hydrometeorology. Journal of Climate and Applied Meteorology 23:201-213.

Wilmking, M., G. P. Juday, V. A. Barber, and H. S. J. Zald, 2004. Recent climate warming forces contrasting growth responses of white spruce at treeline in Alaska through temperature thresholds. Global Change Biology 10:1724-1736.

Received 3 May 2013; accepted 24 March 2014. 